\title{
REPUBLICANISMO(S), DEMOCRACIA, PODER
}

Alessandro Pinzani

RESUMO - Partindo da recente renascença da tradição republicana, o presente trabalho aponta para a pluralidade de tal tradição, para em seguida distinguir entre dois tipos de solução que ela oferece aos problemas da salvaguarda da república e do controle dos efeitos negativos das ações dos indivíduos, a saber, a solução internalista e a solução externalista. Ao analisar esta última serão discutidas questões como: a ficção democrática do "one head, one vote" e a relação entre poder político e poder econômico e social.

PALAVRAS-CHAVE - Republicanismo. Democracia. Poder. Madison.

\begin{abstract}
Taking the recent renaissance of the republican tradition as a starting point, this paper points out to the plurality of this tradition and makes a distinction between the two kinds of solution this tradition gives to the problems of saving the republic and of controlling the negative effects of individual actions: the internalist and the externalist solution. Focusing on the latter, we'll discuss questions such as: the democratic fiction of "one head, one vote" and the relationship between political power and socioeconomic power.

KEY WORDS - Republicanism. Democracy. Power. Madison.
\end{abstract}

\section{Republicanismo e republicanismos}

Nos últimos anos, assistimos à renascença da tradição republicana. O redescobrimento ocorreu principalmente na área anglo-saxônica, em particular graças a Quentin Skinner, Philip Pettit e Maurizio Viroli (vejam-se principalmente Skinner, 1998; Pettit, 1997; Viroli, 1999); mas a onda "neo-republicana" atingiu outros países, incluído o Brasil, onde se desenvolveu um debate vivaz e prolífico (veja-se, por exemplo, Bignotto, 2000 e 2001). O republicanismo brasileiro, contudo, se caracteriza menos pela insistência na temática das virtudes cívicas, típica do republicanismo clássico e do neo-republicanismo, e mais pela preocupação com a necessidade de fortalecer o senso da res publica, da coisa pública, entre os cidadãos - e isso me parece um importante ponto de distinção.

Ora, apesar deste renovado interesse pelas temáticas republicanas, nem sempre fica claro o que se entende por republicanismo. Já em 1819 John Adams (que habitualmente é considerado ele mesmo um republicano) confessava não ter nunca entendido o que seria o republicanismo e afirmava que "nenhuma outra pessoa

Universidade Federal de Santa Catarina - UFSC/CNPq.

\begin{tabular}{|l|l|l|l|l|l|}
\hline VERITAS & Porto Alegre & v. 52 & n. 1 & Março 2007 & p. 5-14 \\
\hline
\end{tabular}


nunca o entendeu ou o entenderá", pois republicanismo "pode significar qualquer coisa, tudo ou nada" (apud Wood, 1991, 95). Mais recentemente, Norberto Bobbio afirmou a mesma coisa no seu diálogo com Maurizio Viroli sobre a república (Bobbio e Viroli, 2001).

De fato, existe uma pluralidade de posições bastante variadas, no âmbito da tradição republicana. Entre os neo-republicanos, Pettit e Viroli tentam elaborar uma teoria mais sistemática, partindo da concepção republicana de liberdade, mas tal tentativa se baseia em distinções insustentáveis entre famílias teóricas e conceitos de liberdade que nunca existiram na forma na qual esses dois pensadores os apresentam. Eles oferecem uma imagem do liberalismo e da liberdade liberal, por um lado, e da democracia radical e da liberdade democrática, por outro, que não corresponde a nenhum modelo concreto e que representa mais uma caricatura polêmica do que um retrato fiel. Por sua vez, Skinner prefere apontar para as raízes históricas do republicanismo, procurando reconstruir a árvore genealógica dessa tradição. Contudo, não é fácil juntar autores tão diferentes como Cícero, Maquiavel, Rousseau ou Madison - para mencionar apenas pensadores clássicos. Por isso, Skinner se limita a incluir na tradição republicana só alguns deles.

Há, depois, muitos autores contemporâneos que preferem referir-se à tradição republicana norte-americana que inicia com Madison e o Federalista, ou a pensadores pós-revolucionários dos séculos XVIII e XIX, como o alemão Julius Fröbel. Penso em Michael Sandel, Charles Taylor, Robert Putnam, Benjamin Barber, Robert Bellah, Richard Dagger, entre outros; mas também em pensadores de área lingüística alemã (como Herfried Münkler, Günter Frankenberg, Helmut Dubiel, Claus Offe e o próprio Jürgen Habermas) e francesa (como Claude Lefort e Marcel Gauchet).

Contudo, ainda reconhecendo que há uma pluralidade de posições que podem ser chamadas de republicanas, deve ser possível identificar um elemento comum, sem o qual não faria sentido utilizar o conceito de republicanismo. Penso que o elemento que reúne os pensadores que se chamam ou são chamados de republicanos possa ser identificado, em primeiro lugar, numa preocupação com a sobrevivência das instituições políticas (uma preocupação aliás muito atual nestes tempos de "crise" ou de "eclipse" da política, para citar os títulos de dois recentes simpósios brasileiros sobre o assunto) e em segundo lugar no fato de ligar essa questão à necessidade de eliminar ou limitar os aspectos mais negativos da ação humana (entre parênteses, gostaria de lembrar que a tradição republicana surge numa época na qual era impossível pensar a política sem referir-se a uma certa concepção da natureza humana e, principalmente, das paixões que determinam as ações humanas; somente a partir de Hegel o modelo das paixões é substituído pelo modelo das necessidades ou carências como moventes da ação humana; desse ponto de vista os neo-republicanos - mas não todos os republicanos contemporâneos - voltam para uma visão característica da primeira modernidade).

A comum preocupação com a salvação da república e a desconfiança na natureza humana dão lugar, contudo, a posições muito diversas entre si. Desse ponto de vista, segundo Robert Dahl, existem pelo menos duas variantes da tradição 
republicana: uma democrática e uma aristocrática (Dahl, 1989, p. 27 e s.). A primeira vê no predomínio de grupos dominantes (política ou economicamente) o risco principal para o Estado. Ela vê na degeneração oligárquica da república o perigo que deve ser evitado custe o que custar. Portanto, ela considera o governo popular ilimitado como o remédio melhor contra tal possibilidade. Seu modelo é a Atenas do ostracismo. A variante aristocrática teme antes as decisões de uma maioria plebéia que ela considera facilmente manipulável e corruptível - certamente incapaz de reconhecer o bem comum. O elemento comum a essas duas variantes é a idéia de que o egoísmo dos cidadãos possa levar à ruína do Estado e que, portanto, é necessário controlar as forças desagregantes desencadeadas pelo fato de os indivíduos perseguirem seus interesses pessoais. A questão do controle do poder de ação dos indivíduos se torna central, portanto, para o pensamento republicano antigo e moderno. A ela são possíveis duas respostas, que Günter Frankenberg chama de externalista e internalista. A primeira consiste em deixar que uma instância externa, por exemplo, o Estado, efetue tal controle. Às leis estatais caberia, então, a função de delimitar as esferas jurídicas dos cidadãos, de proibir ou ordenar certas linhas de ação, e de estabelecer regras para os casos de conflito (Frankenberg, 1997, p. 137).

A solução internalista consiste em incentivar a autodisciplina dos cidadãos. Nesse âmbito recorre-se às idéias de virtudes cívicas, de religião civil e de patriotismo tradicional ou constitucional (ibid., p. 138 s.). Na tradição republicana, assiste-se normalmente a uma mistura destas duas soluções: uma república precisa de leis eficazes e de cidadãos virtuosos. Este que pode parecer um círculo vicioso (sem leis eficazes os cidadãos não seriam virtuosos, mas as leis são eficazes só se os cidadãos são virtuosos) é considerado, pelo contrário, um círculo virtuoso pelos republicanos. A interação destes dois elementos fortalece a república. Num primeiro momento, dir-se-ia que leis eficazes são mais necessárias, pois elas conseguem controlar os aspectos negativos que podem resultar da ação dos cidadãos independentemente do fato de esses últimos serem virtuosos ou não. Já a virtude dos cidadãos parece ser somente uma garantia ulterior e não necessária. Contudo, Maquiavel expressa a firme convicção de que manter um governo livre numa cidade corrompida é tarefa extremamente difícil: "As leis e instituições estabelecidas na origem de uma república, quando os cidadãos eram virtuosos, se tornam insuficientes quando eles começam a se corromper" (Comentários, I, 18, em Maquiavel, 2000, p. 75).

Embora a solução internalista e a externalista habitualmente convivam na mesma teoria, é possível distinguir entre autores que confiam mais nos mecanismos institucionais e autores que colocam a salvação da república principalmente na virtuosidade dos cidadãos. Neste escrito ocupar-me-ei só brevemente da solução internalista e de questões como a virtude cívica, a religião civil e o patriotismo, e concentrarei minha atenção sobre a posição externalista defendida pelos autores que confiam nas instituições como instrumento para garantir a sobrevivência da república. 


\section{A solução internalista}

A idéia de que as virtudes cívicas sejam necessárias para a sobrevivência do Estado constitui seguramente uma das marcas mais características do pensamento republicano antigo e moderno (cf. Sandel, 1995, p. 55; Münkler, 1992, p. 25). Contudo, não há unanimidade entre os republicanos, não somente no que diz respeito à definição de um cânone de virtudes, mas até no que diz respeito às razões para afirmar a necessidade de tais virtudes. Thomas Jefferson, por exemplo, apela para virtudes próprias de uma sociedade agrícola e arcaizante que ele contrapõe ao capitalismo industrial incumbente (Jefferson, 1999, p. 170 e s.). Rousseau oscila entre saudade de um passado idealizado (a Idade Áurea dos cantões suíços) e a esperança de um futuro utópico (como no projeto de Constituição para a Córsega). Pensadores contemporâneos se preocupam, antes, em adaptar o ideal republicano à sociedade moderna - como, por ex., Benjamin Barber, o qual propõe medidas que objetivam promover uma participação política mais ativa por meio dos mais atuais meios técnicos (Barber, 1998). Com certeza, há pelo menos um certo consenso em relação a uma de tais virtudes: a capacidade dos cidadãos de sacrificar seus interesses pelo bem comum (seja este definido como for). Em relação às demais virtudes, o elenco varia muito segundo os autores e inclui atitudes ou traços do caráter que nem sempre se deixam definir facilmente, como, por ex., o amor à pátria. Prevalecem, em geral, as virtudes belicosas, como o patriotismo, a coragem, o valor militar, a abnegação, a disciplina.

No que diz respeito a virtudes menos militares, como, por ex., a solidariedade entre os concidadãos, o respeito às leis (em situações nas quais a punição da violação é improvável), o respeito a estilos e modos de vida diferentes, a tolerância religiosa, a disponibilidade para o diálogo, etc., o republicanismo não se distingue muito do liberalismo, particularmente no caso daqueles autores que falam em "virtudes liberais", como Stephen Macedo, William Galston, Stephen Holmes e Richard Dagger (Macedo, 1990; Galston, 1991; Holmes, 1993; Dagger, 1997), e do próprio Rawls (Rawls, 2000 e 2002), sem falar em pensadores, clássicos como o Locke dos Pensamentos sobre a educação, de John Stuart Mill e do próprio Kant (e sem considerar que até Hobbes afirma que, para a sobrevivência do Leviatã, é preciso que os cidadãos desenvolvam virtudes como a moderação, a justiça, a disponibilidade a perdoar, etc.).

O apelo para o patriotismo, por sua vez, leva quase inevitavelmente a uma certa radicalização do discurso político, pois um patriota convencido de estar perseguindo o bem comum do seu país tenderá a considerar seus adversários políticos como indivíduos cegos e incapazes de enxergar a verdade, ou como inimigos da pátria, ou como ambos (cf. a eficaz descrição da reação dos governantes ao voto branco do povo no Ensaio sobre a lucidez, de Saramago, 2004). Assim, simples conflitos de interesses ou de opiniões se tornam conflitos ideológicos sobre a "verdadeira" natureza da comunidade e dos interesses dela, como reconhece um defensor do ideal das virtudes cívicas, a saber, Michael Walzer (1996, p. 189). 


\section{A solução externalista}

Também a solução externalista admite uma pluralidade de posições. Começarei por aquela que parece ser predominante: a idéia de que os efeitos negativos do egoísmo dos indivíduos podem ser controlados diretamente através de mecanismos institucionais apropriados, sem outra preocupação que a de garantir a igualdade política entre os cidadãos. Essa posição é representada por pensadores clássicos, como Kant e por pensadores contemporâneos, como os representantes de teorias formais ou institucionais da democracia (os neo-republicanos não incluiriam provavelmente estes teóricos na tradição republicana, e talvez com razão: mas acho que há pelo menos uma proximidade teórica entre eles e a posição externalista republicana em questão, como veremos).

Entre os defensores da solução externalista se coloca também a maioria dos Pais Fundadores estadunidenses, como James Madison ou John Adams, que consideravam a Constituição de 1787 como um instrumento para controlar os devastadores efeitos das paixões humanas. Adams, na sua Defesa da Constituição Americana, comentando as Histórias Florentinas do próprio Maquiavel, retoma a visão deste último acerca da natureza humana: os homens são ingratos, volúveis, quérulos, ambiciosos, vaidosos. "A natureza humana é a mesma numa multidão como sobre um trono e [...] as paixões incontroladas são pelo menos tão brutais e diabólicas e o poder ilimitado tão tirânico numa multidão como num monarca ou num senado" (Adams, 2004, p. 310). Contudo, o indivíduo vicioso (seja ele simples cidadão, monarca ou aristocrata) não pode ser culpado, pois a própria natureza humana é viciosa: "Nenhuma nação tem o direito de culpar tal cidadão até ela ter estabelecido uma forma de governo capaz de o proteger, por um lado, e, por outro lado, de proteger o povo contra ele" (ibid., p. 308). A forma de governo em questão é, segundo Adams, o sistema de checks and balances previsto pela Constituição norte-americana de 1787. "Tal Constituição é modelada sobre a natureza humana e toma precauções contra esta última em vez de confiar no que não se pode encontrar nela, a saber: moderação e temperança no exercício do poder" (ibid., p. 319). Isso aparece evidente no célebre artigo 10 do Federalista, no qual Madison se ocupa da questão das facções (Hamilton, Jay e Madison, 2003, p. 79 s.). Não pretendo entrar aqui numa análise da solução oferecida por Madison (cf. Pinzani, 2006). Só gostaria de apontar para um aspecto de tal solução, que considero paradigmática da posição externalista em questão. A maior preocupação de Madison é a de evitar o surgimento e fortalecimento de facções. Com tal fim, ele elabora um sistema que - através dos mecanismos da representação e da divisão do território em distritos eleitorais - deveria impedir que os indivíduos se juntem dando vida a grupos "unidos ou animados por algum impulso comum de paixão ou de interesse adverso aos direitos dos outros cidadãos ou aos interesses permanentes e globais da comunidade", para utilizar a definição madisoniana de facção (Hamilton, Jay e Madison, 2003, p. 80). Na elaboração de seu sistema, Madison se orienta pelo princípio do "one head, one vote", que está na base da assim chamada "democracia madisoniana" (Madison pessoalmente contrapõe seu modelo de democracia 
representativa, que ele chama de "república", àquela que ele chama de "democracia" e que - conforme uma leitura típica da sua época - ele identifica com a democracia direta). Nessa ótica, cada cidadão conta por um e só por um. O voto de um George Washington vale tanto quanto o voto de um John Doe, o voto de um Roberto Marinho tanto quanto o voto de um catador de lixo. Esta concepção determina a visão peculiar que Madison possui do surgimento e fortalecimento das facções: o poder de uma facção aumenta em proporção aritmética ao aumentar do número dos membros dela. Uma facção que reúna 100 indivíduos será mais forte que uma de 50 indivíduos. Contudo, essa visão é baseada numa percepção parcial da realidade de uma sociedade.

O princípio one head, one vote é resultado de uma visão seletiva das possíveis relações entre os membros de uma sociedade. Ela considera tais membros somente do ponto de vista do direito de voto, deixando de lado qualquer outra relação possível que possa existir entre eles. Esta visão seletiva - Žižek falaria de uma parallax view que nos leva a considerar só uma cara da moeda (Žižek, 2006, p. 56) - fornece ainda hoje a base das mencionadas teorias formais ou institucionais da democracia (e nisso consistiria a proximidade teórica entre elas e o republicanismo), mas também de teorias republicanas da democracia como a de Claude Lefort ou de Marcel Gauchet (Lefort, 1986; Gauchet, 2002).

Se, contudo, considerarmos outros aspectos, como, por exemplo, as desigualdades econômicas, as hierarquias sociais, as relações de poder entre governantes e governados, etc., não é possível descrever as relações entre os membros de uma sociedade como relações de absoluta paridade e igualdade conforme o princípio one head, one vote. O mecanismo que leva ao surgimento das facções e que determina sua força relativa age segundo uma proporção geométrica e não aritmética: em primeiro lugar, conta menos o número de indivíduos que se juntam e mais o poder econômico, social ou político possuído por eles; em segundo lugar, quando tais poderes se juntam, o resultado não é dado simplesmente pela soma deles, mas representa uma grandeza bem superior. Ao unir-se com outro poder, um poder gera um novo poder que é maior do que a soma dos dois poderes. Portanto, quanto mais poderosos os membros de uma facção, tanto maior seu poder, independentemente do número. Esta é a razão pela qual os mecanismos previstos por Madison (e pela Constituição de 1787) não impediram o surgimento e o triunfo de facções minoritárias, mas poderosas, capazes de exercer um controle sobre aquelas instituições que deveriam controlá-las. Madison achava que um número pequeno de indivíduos não poderia representar uma ameaça para a república, mas não levou em conta o fato de que o poder de um grupo de indivíduos muda enormemente, se seus membros são, por exemplo, operários ou empresários, jornalistas ou proprietários de jornais. Do ponto de vista formal do direito de voto, o diferente poder econômico e social não significa nada, mas de fato tal diferença se transforma numa diferença notável de peso e de poder políticos. O problema não é simplesmente que a teoria madisoniana ou as teorias formais e institucionais da democracia não conseguem dar conta desse fenômeno. O problema é antes constituído pelo fato de que nossas instituições democráticas e liberais são baseadas 
justamente em tais teorias ou, pelo menos, no princípio do one head, one vote. Elas se sustentam na idéia, ou melhor, na ficção de que todos os cidadãos são iguais e possuem o mesmo poder político, exercido por eles no momento do voto quer nas eleições, quer em plebiscitos, etc. A igualdade jurídica postulada pelas constituições democráticas e liberais esconde uma realidade feita de desigualdade econômica, social e política - uma desigualdade que a igualdade jurídica protege e até fomenta, por exemplo, através da defesa da propriedade privada nãoqualificada, ou seja, de uma defesa geral que não leva em conta a origem e a justiça das concretas relações de propriedade.

Ora, se definirmos democracia como um sistema de governo no qual cada cidadão recebe uma parcela de poder político igual à dos outros (one head, one vote), é evidente que uma distribuição não-igualitária do poder político significa o fim da democracia propriamente dita. Portanto, se considerarmos que, na nossa sociedade, às desigualdades na distribuição do poder econômico e social corresponde uma desigual distribuição do poder político, ela já não se nos mostraria como uma democracia, mas como uma oligarquia na qual o poder político é exercido por uma parcela da sociedade, apesar da existência de mecanismos eletivos democráticos. Não é preciso que essa parcela seja minoritária para falar em oligarquia. O fato de que uma parte dos cidadãos possua um poder político maior do que os outros já é suficiente para isso - a não ser que se ofereça outra definição de democracia ou até de demos.

Existem, contudo, outras posições externalistas que levam em consideração as desigualdades econômicas e sociais e tentam elaborar mecanismos que as reduzam. Um exemplo clássico é o projeto constitucional para a Córsega, de Rousseau, que prevê uma sociedade fechada, economicamente autárquica, baseada numa agricultura de subsistência, na ausência quase absoluta de comércio, na ausência completa do dinheiro, numa imobilidade social e física que impede os indivíduos de mudar, não somente sua posição social, mas até de transferir-se para uma outra cidade, sem perderem seus direitos civis. Trata-se, obviamente, de um modelo inaplicável - não somente nas sociedades contemporâneas, mas já nas sociedades da época de Rousseau, incluída a própria Córsega. Tal modelo representa um caso-limite entre as posições em questão. Mas em geral todos os republicanos clássicos apontam para a necessidade de uma certa igualdade econômica entre os cidadãos, a fim de que não se crie uma situação na qual indivíduos ou grupos poderosos consigam controlar os votos dos concidadãos e a própria república. ${ }^{1}$ Isso leva vários autores (incluindo-se Kant) a excluir do número dos cidadãos politicamente ativos (ou seja, detentores de um direito ativo e passivo de voto) aqueles que não possuem independência econômica, a saber, todos os que

\footnotetext{
Julius Fröbel, por exemplo, avança a exigência de uma "justa distribuição dos bens", a fim de que surja "uma república social, ou seja, um Estado no qual a felicidade, a liberdade e a dignidade de cada indivíduo sejam reconhecidas como uma finalidade comum para todos e o poder jurídico e político da sociedade derive da compreensão e do acordo recíprocos de todos os seus membros" (Fröbel apud Frankenberg, 1997, p. 103 s.).
} 
dependem de outros para sua sobrevivência: mulheres, crianças, mas também assalariados, pois eles não teriam interesses a defender, e poderiam, portanto, facilmente entregar seus votos a quem quisesse comprá-los em troca de dinheiro ou de favores. O problema dessa posição é o oposto daquele da ficção do one head, one vote: nesse caso, não se fala na igualdade dos cidadãos, mas só são levadas em conta as desigualdades econômicas e sociais - paradoxalmente em prol daqueles que tiram proveito de tais desigualdades! (Entre parênteses: cabe salientar que são sempre os pobres a ser censurados e punidos preventivamente, enquanto a sede de poder, o egoísmo e as tendências corruptoras dos ricos são aceitas como fatos naturais: não é o rico que tenta comprar votos e ser punido com a exclusão do voto, mas o miserável que trocaria seu voto por um pedaço de pão. Da mesma maneira, se um governo concede desagravos fiscais às classes altas, está agindo legitimamente; se outro governo implementa programas assistenciais aos miseráveis, está comprando votos.)

Uma solução alternativa consistiria na tentativa de conciliar as duas posições: manter a igualdade política e tentar instaurar uma maior igualdade econômica e social. Seguindo Jacques Rancière, poderíamos, por exemplo, conceber a política como discussão sobre a definição do próprio demos e sobre o sentido da igualdade dos cidadãos (Rancière, 1996). Nessa ótica, a solução do problema da desigualdade permaneceria uma solução política, fruto, não do consenso, mas do litígio. $\mathrm{Na}$ visão da política como luta, a desigualdade pode ser abolida ou reduzida só se vencer o partido dos que querem sua abolição ou redução. ${ }^{2}$ A idéia de uma tomada democrática do poder político, a fim de efetuar as necessárias transformações econômicas e sociais, é um topos da tradição social-democrática e esquerdista em geral.

Só que essa via democrática à transformação social é possível somente através de uma escolha democrática, cujo maior obstáculo é representado precisamente por aqueles grupos, cujo poder deveria ser reduzido e que controlam o mecanismo de decisão democrática. Claro, parece tratar-se, nesse caso, da constatação empírica de um mero acidente, de uma simples contingência, e não de um argumento de princípio. Contudo, estou perguntando-me justamente se a democracia liberal não represente de princípio um obstáculo para uma democracia, por assim dizer, substancial, a saber, uma democracia na qual, ou não existam desigualdades econômicas e sociais, ou a tais desigualdades não corresponda uma desigualdade na distribuição do poder político. Já que a primeira hipótese parece francamente utópica, deveríamos perguntar-nos se e como seria possível impedir que o poder econômico e social se traduza em poder político. Para responder a essa pergunta, é necessária uma reflexão prévia sobre o próprio conceito de poder.

O republicanismo opera tal reflexão, mas permanece numa visão tradicional do poder, definido por ele como a capacidade de influenciar as ações de outros

Talvez seja por isso que muitos teóricos de esquerda procuraram e encontraram inspiração em Carl Schmitt, não somente a fim de criticar a democracia liberal, mas a fim de reinterpretar a luta de classe efetuada com meios democráticos como confrontação de amigo e inimigo. 
indivíduos, conforme sustenta Pettit em seu livro de 1997 (Pettit, 1997). Há aqui uma dupla redução: em primeiro lugar, não se considera que o poder poderia ser definido também como a capacidade de influenciar o tipo de pessoa que os outros vão ser. Para dar um exemplo que fique em âmbito político, políticas de inclusão educacional mudam literalmente a vida dos envolvidos e fazem deles outras pessoas; e o mesmo vale para políticas de exclusão. Em segundo lugar, o poder em questão, embora definido de forma geral, acaba sendo pensado exclusivamente como poder político ou jurídico. Assim, o problema da legitimação é colocado unicamente em relação a instâncias detentoras de tal poder, quase nunca, porém, com respeito a instâncias detentoras de poder econômico, religioso ou cognitivo. Deparamo-nos novamente, nesta ocasião, com uma visão parcial que exclui aspectos centrais da vida dos indivíduos, como os ligados à economia, à produção e difusão de saber e de tecnologias, à religião. De todos os efeitos da globalização, o mais evidente é o retrocesso da política em relação aos âmbitos que acabo de mencionar. Evidente para todos, menos para muitos teóricos, que pensam que a solução para a crise da política, que também eles lamentam, deva consistir no desenvolvimento de virtudes cívicas, de uma religião civil ou de um patriotismo constitucional ou tradicional. A crise da política não é crise de motivação ou de participação, antes é uma crise bem mais profunda, pois diz respeito à própria essência da política.

O republicanismo não consegue, na minha visão, oferecer uma solução convincente para este problema - quer seja uma solução externalista, quer se trate de uma solução internalista -, pois ele se concentra nos aspectos estritamente políticos, tentando desenvolver, na melhor das hipóteses, mecanismos institucionais incapazes de lidar com a transformação em poder político de outros poderes. De outro lado, parece que a filosofia política atual (a neo-republicana, como as teorias da democracia institucional, participativa e deliberativa) não tem a capacidade teórica de pensar o poder de outra forma que não como poder político ou jurídico. Para citar Foucault: ela ainda não conseguiu cortar a cabeça do rei (Foucault, 1988, p. 86). Nesse sentido, há mister, não de republicanismo, mas de uma república teórico-política.

\section{Referências}

ADAMS, John. The portable John Adams. London: Penguin, 2004.

BARBER, Benjamin. A place for us. How to make society civil and democracy strong. New York: Hill and Wang, 1998.

BOBBIO, Norberto e VIROLI, Maurizio. Dialogo intorno alla repubblica. Roma e Bari: Laterza, 2001.

DAGGER, Richard. Civic virtues. Rights, citizenship, and republican liberalism. Oxford: Oxford University Press, 1997.

DAHL, Robert A. Democracy and its critics. New Haven / London: Yale University Press, 1989.

FOUCAULT, Michel. A vontade de saber. História da sexualidade 1, Rio de Janeiro: Graal, 1988.

FRANKENBERG, Günter. Die Verfassung der Republik. Autorität und Solidarität in der Zivilgesellschaft. Frankfurt a. M.: Suhrkamp, 1997. 
GALSTON, William. Liberal purposes. Goods, virtues, and diversity in the liberal state. Cambridge: Cambridge University Press, 1991.

GAUCHET, Marcel. La démocratie contre elle-même. Paris: Gallimard, 2002.

HAMILTON, Alexander; JAY, John; MADISON, James. O Federalista. Org. de V. Soromenho-Marques. Lisboa: Colibri, 2003.

HOLMES, Stephen. The anatomy of antiliberalism. Cambridge (MA) / London: Harvard University Press, 1993.

JEFFERSON, Thomas. Notes on the State of Virginia. London: Penguin, 1999.

LEFORT, Claude. Pensando o político. Ensaios sobre democracia, revolução e liberdade. São Paulo: Paz e Terra, 1986.

MACEDO, Stephen. Liberal virtues. Citizenship, virtue and community in liberal constitutionalism. Oxford: Clarendon Press, 1990.

MAQUIAVEL, Nicolau. Comentários sobre a primeira década de Tito Lívio. 4. ed. Brasília: Editora da UnB, 2000.

MÜNKLER, Herfried. Politische Tugend. Bedarf die Demokratie einer sozio-moralischen Grundlegung?. In: Idem (org.). Die Chancen der Freiheit. Grundprobleme der Demokratie. München / Zürich: Piper, 1996, 25-46.

PETTIT, Philip. Republicanism. A theory of freedom and government. Oxford: Oxford University Press, 1997.

PINZANI, Alessandro. Os demônios e as facções. Kant e Madison sobre paixões e instituições. In: Crítica, 33 (no prelo).

RANCIÈRE, Jacques. O desentendimento. Política e filosofia. São Paulo: Editora 34, 1996.

RAWLS, John. O liberalismo político. 2. ed. São Paulo: Ática, 2000.

. Uma teoria da justiça. 2. ed. São Paulo: Martins Fontes, 2002.

SANDEL, Michael. Liberalismus und Republikanismus. Von der Notwendigkeit der Bürgertugend. Wien: Passagen, 1995.

SARAMAGO, José. Ensaio sobre a lucidez. São Paulo: Companhia das Letras, 2004.

WALZER, Michael. Zivile Gesellschaft und amerikanische Demokratie. Frankfurt a. M.: Fischer, 1996.

WOOD, Gordon S. The radicalism of the American Revolution. New York: Vintage, 1991.

ŽIŽEK, Slavoj. The Parallax View. Cambridge (MA): The MIT Press, 2006. 